\title{
Down-regulation of RFWD3 inhibits cancer cells proliferation and migration in gastric carcinoma
}

\author{
Jia Jia ${ }^{1}$, Yanguo Yang ${ }^{1}$, Tingting Yan ${ }^{1}$, Tao $\mathrm{Chen}^{2}$ and Guangxin $\mathrm{Lu}^{1}$ \\ ${ }^{1}$ Department of Gastroenterology, Renmin Hospital, Hubei University of Medicine, Shiyan, Hubei, China \\ ${ }^{2}$ Department of Neurology, Renmin Hospital, Hubei University of Medicine, Shiyan, Hubei, China
}

\begin{abstract}
The E3 ligase RING finger and WD repeat domain 3 (RFWD3) can stabilize p53 in response to DNA damage, participate in replication checkpoint, and have an important role in multiple myeloma, testicular germ cell tumor and lung carcinogenesis. Its expression and molecular mechanisms have never been explored in gastric cancer. In present study, the RFWD 3 was found over-expressed in the both AGS and HGC-27 gastric cancer cells. Knockdown of RFWD3 suppressed cells proliferation activity of gastric cancer cells. Further study showed that the down-regulation of RFWD3 promotes cell apoptosis, suppresses cell migration and invasion and blocks G2/M cell cycle progression, which may be related with AKT, ERK/P38 and Slug pathways. In summary, the results of the present study showed that RFWD3 might be an oncogene candidate for gastric cell proliferation and may have an important role in gastric carcinogenesis.
\end{abstract}

Key words: RFWD3 - Gastric carcinoma - Cell proliferation - Cell migration

\section{Introduction}

Gastric cancer is the fifth most frequent malignancy and the third leading cause of cancer death worldwide, accounting for $\sim 723,000$ deaths annually (Ferlay et al. 2015). However, most patients are diagnosed at an advanced stage of the disease. Although advanced gastric cancer is, in general treated with surgery and/or chemotherapy, the overall 5-year survival rate is less than 24\% (Lordick et al. 2017; Russo et al. 2019). Gastric cancer is a complex disease characterized by the accumulation of multiple genetic and epigenetic alterations to oncogenes, which disturb the expression of genes controlling critical regulatory processes (Rocken et al. 2017; Birkman et al. 2018). However, the exact molecular mechanisms underlying gastric cancer initiation and progression are still not well understood, which prevent the develop-

Correspondence to: Tao Chen, Department of Internal Medicine, Renmin Hospital, Hubei University of Medicine, Shiyan, Hubei, 442000, China

E-mail: Sychent2009@163.com

Guangxin Lu, Department of Gastroenterology, Renmin Hospital, Hubei University of Medicine, Shiyan, Hubei, 442000, China

E-mail: 346639001@qq.com ment of personalized and suitable cancer therapy strategies. Therefore, it is critical to discover reliable prognosis and therapeutic molecular biomarkers for gastric carcinoma and targeted treatment gastric cancer.

The ubiquitin proteasome system (UPS) is one of the important signal transduction pathways ( $\mathrm{Mu}$ et al. 2007). Ataxia Telangiectasia-mutated (ATM) and ATM-Rad3related (ATR) are two key kinases in UPS (Mu et al. 2007; Kitajima et al. 2018). Recent studies have found that the E3 ligase RING finger and WD repeat domain 3 (RFWD3 or RNF201/FLJ10520) was identified as a phosphorylation substrate protein of the ATM/ATR (Mu et al. 2007; Kitajima et al. 2018). RFWD3 can positively regulate p53 stability in response to DNA damage when the G1 cell cycle checkpoint is activated (Fu et al. 2008). RFWD3 functionally interacted and participated in replication checkpoint control, and also respond to replication protein A (RPA)-mediated DNA damage in cancer cells (Gong et al. 2011; Liu et al. 2011). Besides, study showed that RFWD3 is necessary for replication fork restart, normal repair kinetics during replication stress, and homologous recombination (HR) at stalled replication forks (Inano et al. 2017). Biallelic mutations have been found in RFWD3 in patients with Fanconi anemia, which contributes to this disease (Knies et al. 2017). A genome-wide association study demonstrated 
that RFWD3 is a susceptible site for malignant neoplasms, including multiple myeloma and testicular germ cell tumor (Chung et al. 2013; Mitchel et al. 2016). Recently, Zhang et al. (2019) found that RFWD3 is more elevated in tumor samples than in paired normal lung tissues and is inversely associated with the clinical outcome of patients with nonsmall cell lung cancer, which suggest that RFWD3 may have an important role in lung carcinogenesis. However, the significance and elaborate molecular mechanisms of RFWD3 in gastric cancer remains to be elucidated, although a research showed 125I seed irradiation can partly inhibit growth of gastric cancer xenografts via up-regulating the expression level of RFWD3 (Ma et al. 2019).

Here, we obtained the RFWD3 through a series of data standardization and statistical analysis from The Cancer Genome Atlas Database (TCGA), and further examined the function of RFWD3, in terms of cell proliferation, migration, and explored possible molecular mechanism in gastric carcinoma.

\section{Materials and Methods}

\section{TCGA analysis}

We collected the transcriptomic and clinical phenotype information of the gastric cancer-related tissues from TCGA database. The database was applied to predict the target genes of the potential differentially expressed RNA and the considerable amount of transcriptomic data provided the gene expression level of RFWD3.

\section{Cell culture}

Human gastric epithelial cell lines GES-1, human gastric cancer cell lines SGC-7901, MGC-803, AGS and HGC-27 were obtained from the Institute of Biochemistry and Cell Biology, Chinese Academy of Sciences. All cells were cultured in RPMI 1640 medium containing 10\% fetal bovine serum and $1 \%$ streptomycin, and all cells were cultured in incubator containing $5 \% \mathrm{CO}_{2}$ at $37^{\circ} \mathrm{C}$.

\section{Gastric cell transfections for gene silencing}

To knockdown RFWD3 expression, AGS and HGC-27 cells were plated in 6-well plates at a density of $3 \times 10^{5}$ and cultured for $24 \mathrm{~h}$. shRNA against RFWD3 or non-targeting control were transfected using lipofectamine ${ }^{\mathrm{TM}} 2000$ reagent (shRFWD3). Culture medium was replaced with fresh medium after $6 \mathrm{~h}$ and cells were incubated for an additional $24 \mathrm{~h}$. A pool of shRNA against RFWD3 was used. Sequence: (sense: 5'-TGA AGAGTTGCAGGTGTCTAGT-3', antisense: 5'-TAGAAGCAGAAGGTAGCAGAG G-3').

\section{Cell proliferation assay}

AGS and HGC-27 cells (shRNA NC and shRFWD3) were seeded into 96 -well plates $\left(5 \times 10^{4}\right.$ cells/well) and were allowed to attach overnight in complete growth media. After culturing for $24,48,72$ and $96 \mathrm{~h}$, cell proliferation was evaluated by thiazolyl blue tetrazolium bromide (MTT) assay.

\section{Flow cytometric analysis of cell apoptosis}

AGS and HGC-27 cells (shRNA NC and shRFWD3) were seeded into 6 -well plates $\left(3 \times 10^{5}\right.$ cells/well) and were allowed to attach overnight in complete growth media. Cells were collected by the pancreatin without EDTA, stained with $5 \mu \mathrm{l}$ AnnexinV-APC and $5 \mu \mathrm{l}$ 7-AAD for 5-15 min at room temperature avoiding light, and immediately analyzed on FACSCalibur flow cytometer.

\section{Cell migration assay}

AGS and HGC-27 cells (shRNA NC and shRFWD3) were seeded into 6-well plates $\left(3 \times 10^{5}\right.$ cells/well) and grown to $90 \%$ confluence. We scratched the cells in the same way with using a sterile pipette tip and washed with PBS to remove the floating cells, then cells were allowed to attach for $24 \mathrm{~h}$. Resulting images were captured with a microscopic camera system.

\section{Cell invasion assay}

AGS and HGC-27 cells (shRNA NC and shRFWD3) were seeded into 24 -well plates $\left(2 \times 10^{5}\right.$ cells/well $)$ and were allowed to attach overnight in complete growth media. Coating Matrigel was plated in the upper chamber before the seeding of cells. The lower chamber was filled with medium containing $10 \%$ FBS as a chemoattractant. Cells were incubated for $24 \mathrm{~h}$ at $37^{\circ} \mathrm{C}$ and invade through the matrigel. The cells adhered to the lower chambers were fixed using $4 \%$ paraformaldehyde for $30 \mathrm{~min}$ and stained using $0.5 \%$ crystal violet for $20 \mathrm{~min}$, photographed by inverted microscope.

\section{Flow cytometric analysis of cell cycle}

AGS and HGC-27 cells (shRNA NC and shRFWD3) were seeded into 6 -well plates $\left(3 \times 10^{5}\right.$ cells/well $)$ and were allowed to attach overnight in complete growth media. All cells were harvested by digesting with trypsin and washed with PBS and then fixed with ice-cold $70 \%$ ethanol in PBS for $30 \mathrm{~min}$ at $-20^{\circ} \mathrm{C}$. Fixed cells were washed with PBS, treated with $10 \mu \mathrm{l}$ RNase $\mathrm{A}(1 \mathrm{mg} / \mathrm{ml})$ and resuspended in $10 \mu \mathrm{l}$ of $400 \mu \mathrm{g} / \mathrm{ml}$ propidium iodide (PI) for staining. Cell cycle distribution was performed with FACSCalibur flow cytometer. 


\section{RT-PCR analysis}

AGS and HGC-27 cells (shRNA NC and shRFWD3) were washed with PBS and collected for RT-PCR. The primers designed for RFWD3 were 5'-TGAAGAGTTGCAGGTGTCTAGT-3' as forward and 5'-TAGAAGCAGAAGGTAGCAGAGG-3' as reverse. Then, reverse transcription was performed as following: $50^{\circ} \mathrm{C}$ for $1 \mathrm{~min}$ for the reverse transcription. Thermal cycles were: at $95^{\circ} \mathrm{C}$ for $10 \mathrm{~min}$, then 40 cycles at $95^{\circ} \mathrm{C}$ for $30 \mathrm{~s}$, at $60^{\circ} \mathrm{C}$ for $30 \mathrm{~s}$. For RT-PCR analysis, the GAPDH was used as the internal control.

\section{Western blot analysis}

AGS and HGC-27 cells (shRNA NC and shRFWD3) were seeded into 6 -well plates $\left(3 \times 10^{5}\right.$ cells/well) and were allowed to attach overnight in complete growth media. The cells were lysed in protein lysate buffer for $10 \mathrm{~min}$. Total proteins were centrifuged at $12,000 \mathrm{rpm}$ for $10 \mathrm{~min}$ at $4^{\circ} \mathrm{C}$ and quantified. Protein samples were separated with $10 \%$ SDS-PAGE gel. After electrophoresis, the proteins in the gel were transferred to PVDF membrane, incubated with $5 \%$ skim milk for $1.5 \mathrm{~h}$. After overnight incubation with the primary antibody, protein samples were incubated with HRP-conjugated secondary antibodies for $1 \mathrm{~h}$. The results were detected by Quantity One software. The anti-RFWD3, anti-P-P38, anti-P38, anti-P-ERK, anti-ERK, anti-Slug, anti$\mathrm{P}-\mathrm{AKT}$, anti-AKT, anti-E-Cadherin, anti-N-Cadherin, anti$\beta$-actin, goat anti-rabbit IgG-HRP, goat anti-mouse IgG-HRP antibodies were obtained from Santa Cruz Biotechnology.

\section{Statistical analysis}

Data were expressed as means \pm SEM of three independent experiments. Student's $t$-test and two-way ANOVA were employed to analyze the statistical comparisons between sets of data. Significant differences were established at $p<0.05$.

\section{Results}

\section{RFWD3 expression was increased in gastric carcinoma}

We conducted a systematic analysis by data standardization and statistical analysis from TCGA, and RFWD3 was unveiled (Fig. 1A). Specifically, 32 pairs of gastric carcinoma
A

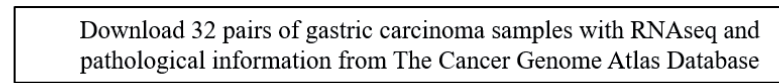

pathological information from The Cancer Genome Atlas Database
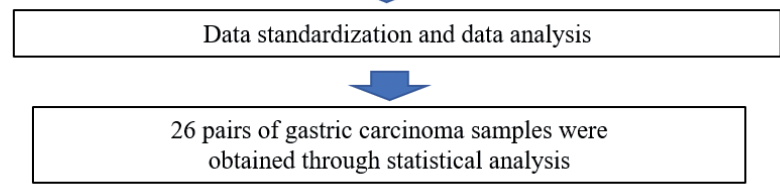

obtained through statistical analysis

Candidate difference gene acquisition
C

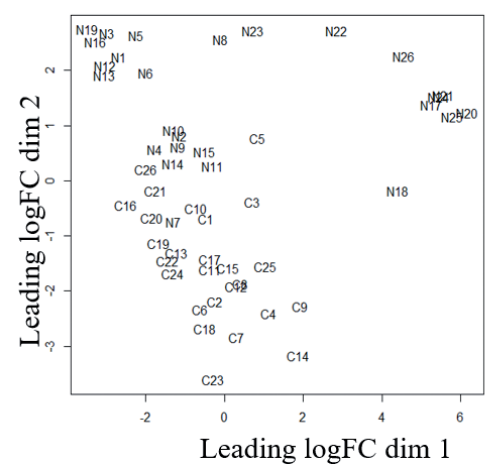

D

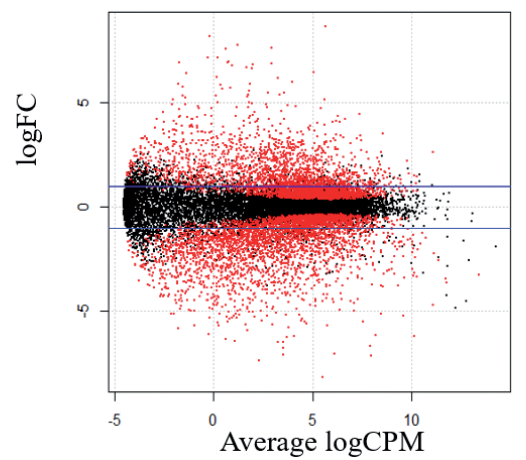

B
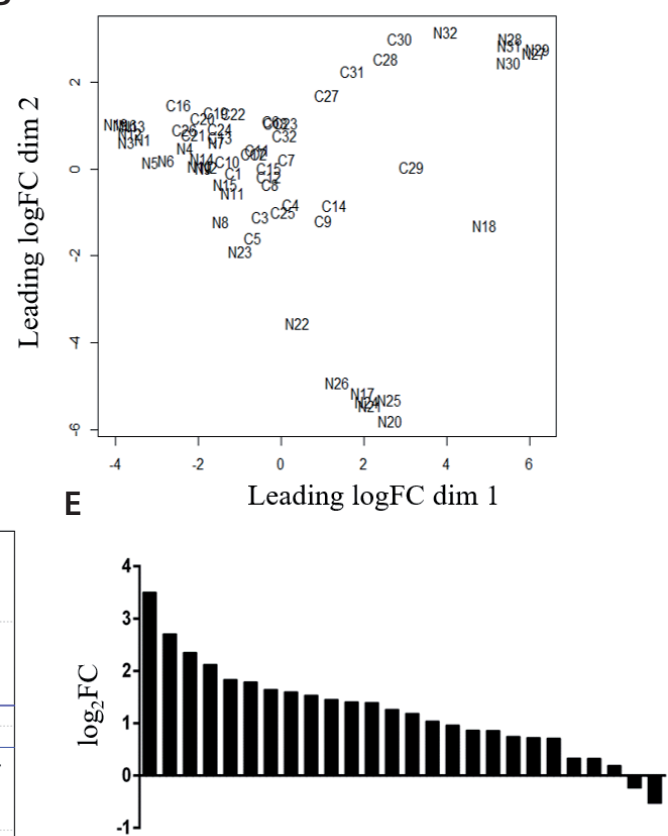

Samples

Figure 1. RFWD3 expression was increased in gastric carcinoma. A. Schematic of the study workflow. B. Distribution of biological differences of 32 pairs of gastric carcinoma samples. C. Distribution of biological differences of 26 pairs of gastric carcinoma samples. D. Distribution of differentially expressed genes in 26 pairs of gastric cancer samples. E. RFWD3 level in the tumor samples of 26 gastric carcinoma from TCGA. N, normal sample; C, cancer sample; FC, fold change. 
samples with RNAseq and pathological information from TCGA were downloaded; we performed data filtering and data standardization. The results showed that there are differences between the majority of the normal samples and cancer samples, while samples 27-32 lacked of biological differences (Fig. 1B). Therefore, a total of 26 pairs of gastric carcinoma samples were identified, and further performed data standardization (Fig. 1C). Next, we analyzed the differential genes of 26 pairs of gastric carcinoma samples candidate genes (Fig. $1 D$ ), and $R F W D 3$ was identified. As shown in Figure 1E, we further found that RFWD3 is elevated in the tumor samples of 15 gastric carcinomas. Based on above results, RFWD3 may be a candidate tumor oncogene in gastric cancer.

\section{Low expression of RFWD3 suppressed gastric cancer cells proliferation}

Furthermore, the expression level of RFWD3 in gastric cells was evaluated by RT PCR. It is noted that compared with normal gastric cells GES-1, the RFWD3 was over-expressed in gastric cancer cells (Fig. 2A). These data demonstrated that RFWD3 overexpression in gastric carcinoma and down- regulation of RFWD3 may be a potential strategy for gastric cancer treatment. In order to illustrate $R F W D 3$ is a candidate tumor oncogene in gastric cancer, based on the fact that RFWD3 expression displayed relative higher level in AGS and HGC-27 cells compared with other gastric cancer cells (Fig. 2A), AGS and HGC-27 cells were chosen for the following experiments. We verified the results by transfecting shRFWD3 in AGS and HGC-27 cells (Fig. 2B-D). If true, the low expression of $R F W D 3$ would be expected to decrease the proliferation effect in gastric cancer. To test this, we evaluated the inhibitory activity in vitro against the growth of AGS and HGC-27 cells. Our results showed, that down-regulation of $R F W D 3$ reduces cell proliferation in time-dependent manner, which suggested that RFWD3 may have important roles in the development of gastric cancer (Fig. 2E,F).

\section{Low expression of RFWD3 promoted gastric cancer cells apoptosis}

Admittedly, apoptosis is recognized as the classical form of programmed cell death, which plays a crucial role in animal processes, tissue homeostasis and pathogenesis (Adams et
A

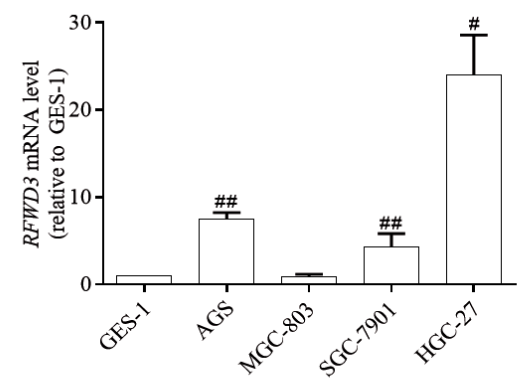

C

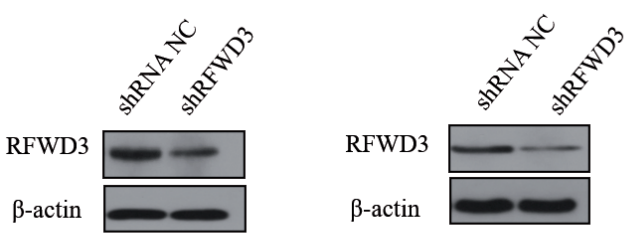

E

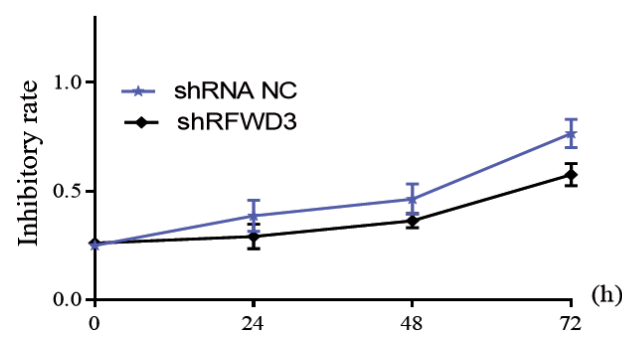

B

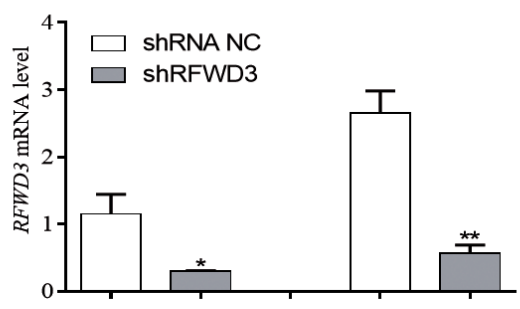

D

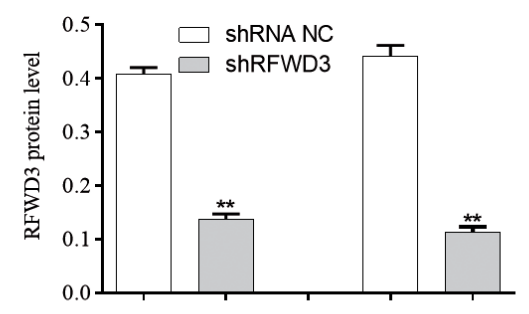

$\mathbf{F}$

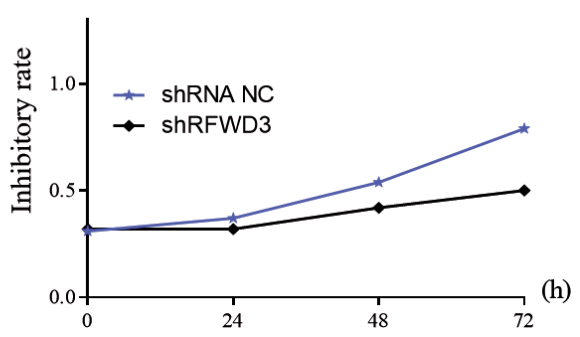

Figure 2. $R F W D 3$ is required for gastric cancer cells proliferation. A. The expression level of RFWD3 in various gastric cancer cells. The AGS and HGC-27 cells were transfected with shRFWD3, transfection efficacy was tested and evaluated using realtime RT-PCR (B) and Western blot analysis (C, D). Cell proliferation of the AGS (E) and HGC-27 (F) cells transfected with shRFWD3. ${ }^{*} p<0.05,{ }^{* *} p<0.01, v s$. shRNA NC; $\# p<0.05$, $\# \#<0.01$ vs. GES-1. 
al. 2018). To explore whether the inhibitory effect of low expression of RFWD3 on gastric cell growth is related to cell apoptosis, AnnexinV-APC/7-AAD double-staining assay was performed. As shown in Figure $3 \mathrm{~A}$ and $\mathrm{B}$, the results indicate that compared with shRNA NC (negative control) group, down-regulation of RFWD3 results in increasing the number of apoptotic cells, suggesting that low expression of RFWD3 exhibits a powerful pro-apoptotic effect.

Low expression of RFWD3 suppressed gastric cancer cells migration and invasion

Metastasis is a major cause of death in gastric carcinoma patients because cancer cells have a potent ability of migration (Han et al. 2019; Jiang et al. 2019). Therefore, we further investigated the effect of RFWD3 on cells migration capability using wound healing assay. In this study, AGS and HGC-27 cells were transfected shRFWD3 before creating the scratch in the confluent monolayers of cultured cells. After the treatment of $0 \mathrm{~h}$ and $24 \mathrm{~h}$, we captured the images of the injured area. As shown in Figure 4A and B, the scratched area of shRNA NC group was mostly healed, while cell migration was significantly decreased in $\operatorname{sh} R$ FWD3 group after $24 \mathrm{~h}$ incubation. In general, tumor cells have greater adaptability to the environment and fortissimo independent survival, and can infinitely invade. To measure the effect of RFWD3 low-expression on tumor cell invasion, cells growing in the log phase were collected and cultured on transwell apparatus. After $24 \mathrm{~h}$ incubation, down-regulation of RFWD3 significantly decreased invasiveness, compared with the shRNA NC group. These results demonstrated that $R F W D 3$ low-expression reduces the migration and invasion of gastric cancer cells (Fig. 4C,D).

\section{Low expression of RFWD3 blocked cell cycle progression}

Generally, preventing the growth of cancer cells by altering the regulation of cell cycle at a specific checkpoint is related with the various tumor developments (Wang et al. 2018). Fu et al. (2019) found that RFWD3 could stabilize p53 in response to DNA damage when the cell cycle checkpoint was activated, which showed RFWD3 may be associated with cell cycle arrest. In the present study, the cell cycle event mediated by RFWD3 was investigated on the gastric cancer cell lines AGS and HGC-27 cells. As shown in Figure $5 \mathrm{~A}$ and $\mathrm{B}$, down-regulation of RFWD3 resulted in an accumulation of cells in $\mathrm{G} 2 / \mathrm{M}$ phase, which indicate that RFWD3-induced G2/M phase of cell cycle arrest may be one of the mechanisms of gastric cancer cell growth inhibition.

\section{RFWD3 may be involved in AKT, ERK/P38 and Slug pathway}

Evidence has revealed that many oncogenes and tumor suppressor genes are directly involved in regulation of
A

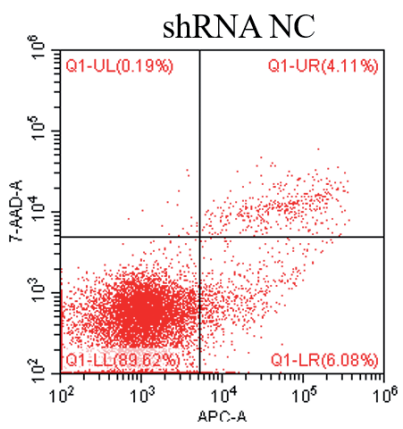

B

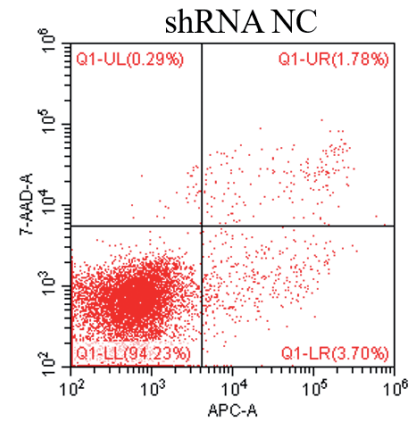

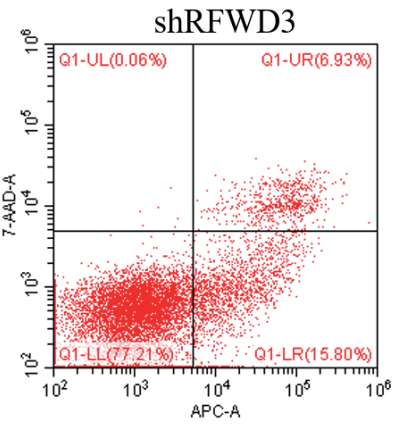
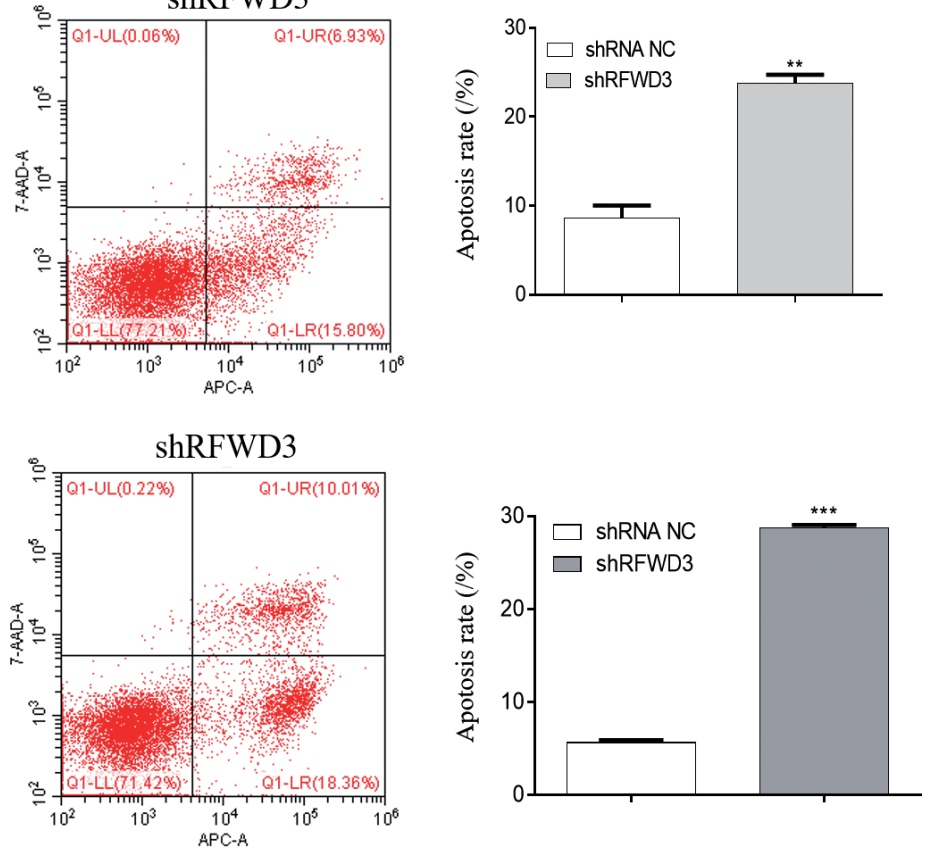

Figure 3. Gastric cancer cell apoptosis of the AGS (A) and HGC-27 (B) cells transfected with shRNA NC or shRFWD3. ${ }^{* *} p<0.01$, ${ }^{* * *} p<0.001$ vs. shRNA NC. 
A

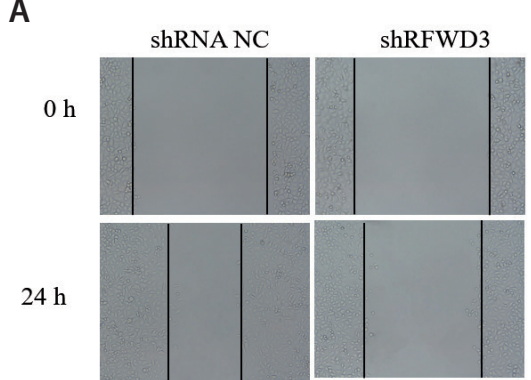

C
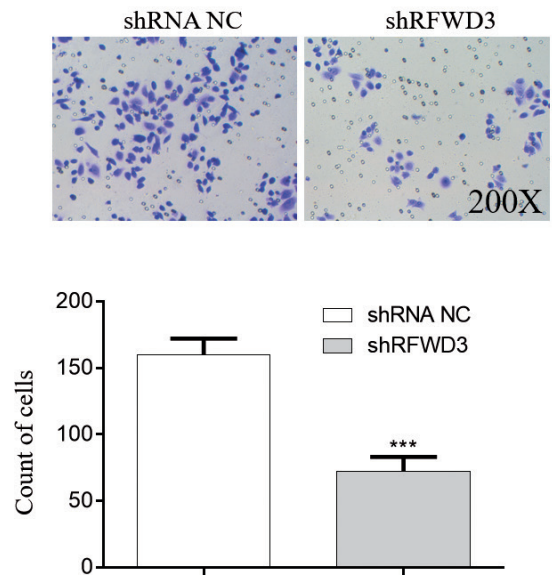

$\overline{\mathbf{B}}$

$0 \mathrm{~h}$

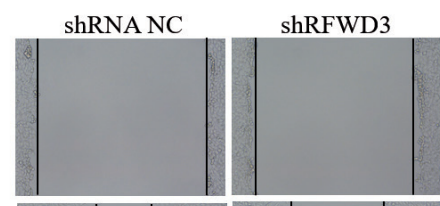

$24 \mathrm{~h}$

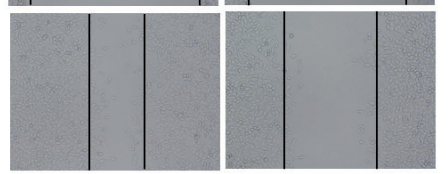

D shRNANC ShRFWD3
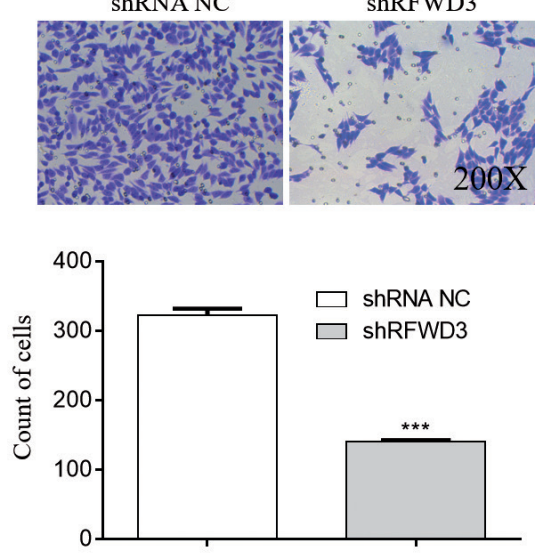

Figure 4. The migration and invasion activity of gastric cancer cells AGS (A and C) and HGC-27 (B and $\mathbf{D})$, transfected with shRNA NC or shRFWD3. ${ }^{* * *} p<0.001 v s$. shRNA NC. intrinsic or extrinsic pathway (Desterro et al. 2019). In exploring the molecular mechanism caused by RFWD3 low-expression in AGS and HGC-27 cells, we found that PP38, P-ERK, P-AKT protein expression levels are decreased in shRFWD3 cells compared with shRNA NC-treated cells.
It also indicated that Slug and N-Cadherin protein expression levels are decreased, while the expression level of ECadherin is increased (Fig. 6A,B). These data all showed that RFWD3 may be involved in AKT, ERK/P38 and Slug pathway-related cell apoptosis.
A
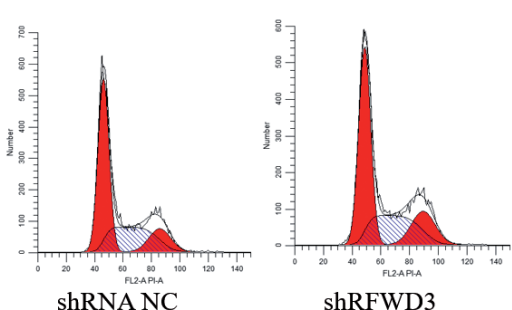

B

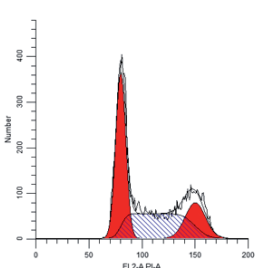

shRNA NC

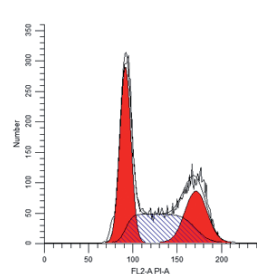

shRFWD3

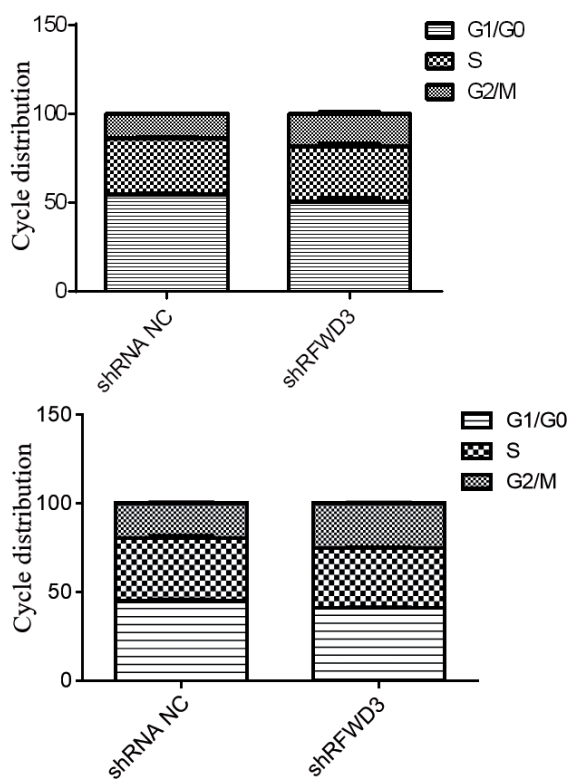

Figure 5. The cell cycle progression of gastric cancer cells AGS (A) and HGC-27 (B) transfected with shRNA NC or shRFWD3. 


\section{Discussion and Conclusion}

Gastric cancer is a common malignancy of human digestive system which has high incidence and mortality worldwide (Ferlay et al. 2015). Gastric cancer occurs without exhibiting specific clinical manifestations. Therefore, it is important to identify tumor markers with high sensitivity and specificity for clinical screening for early gastric cancer. Moreover, chemotherapies against gastric cancer with cytotoxic drugs are not sufficiently efficient.

Personalized postoperative adjuvant chemotherapy using biomarkers is a promising treatment strategy for improving outcomes of patients with advanced gastric cancer (Esfandi et al. 2019). Increasing studies have proved that tumor sup- pressor genes or oncogenes are aberrantly expressed and involved in the initiation and development of gastric cancer (Yan et al. 2018; Zhang et al. 2018; Jia et al. 2019). Thus, exploring the biological function of tumor suppressor genes or oncogenes can be useful for finding novel biomarkers and understanding the mechanism of gastric cancer progression.

In the present study, TCGA database showed that the expression of RFWD3 is significantly higher in gastric cancer tissues compared with those in matched para-tumorous tissues. Furthermore, RT-PCR showed that the level of $R F W D 3$ was significantly increased among the gastric cancer cells, specially, in AGS and HGC-27 cells. In order to demonstrate that high expression of RFWD3 is related to the gastric cancer cells proliferation, we down-regulated the
A
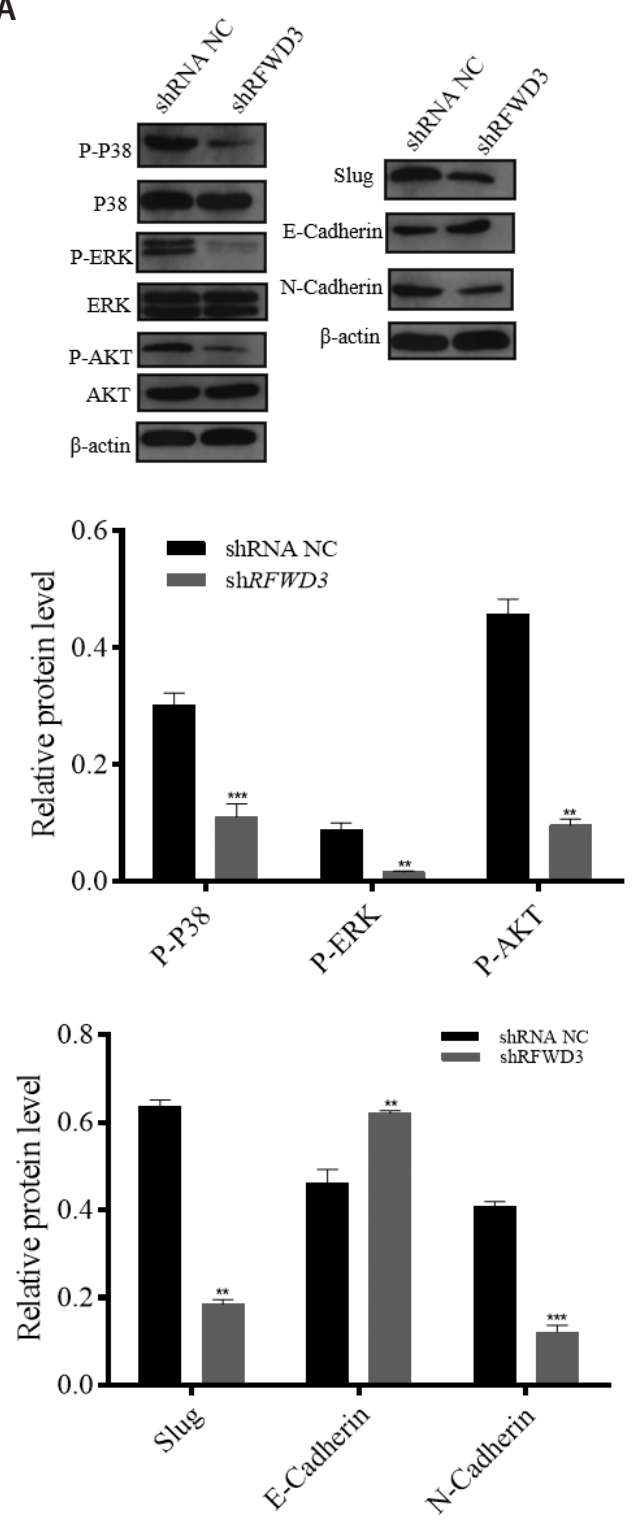

B
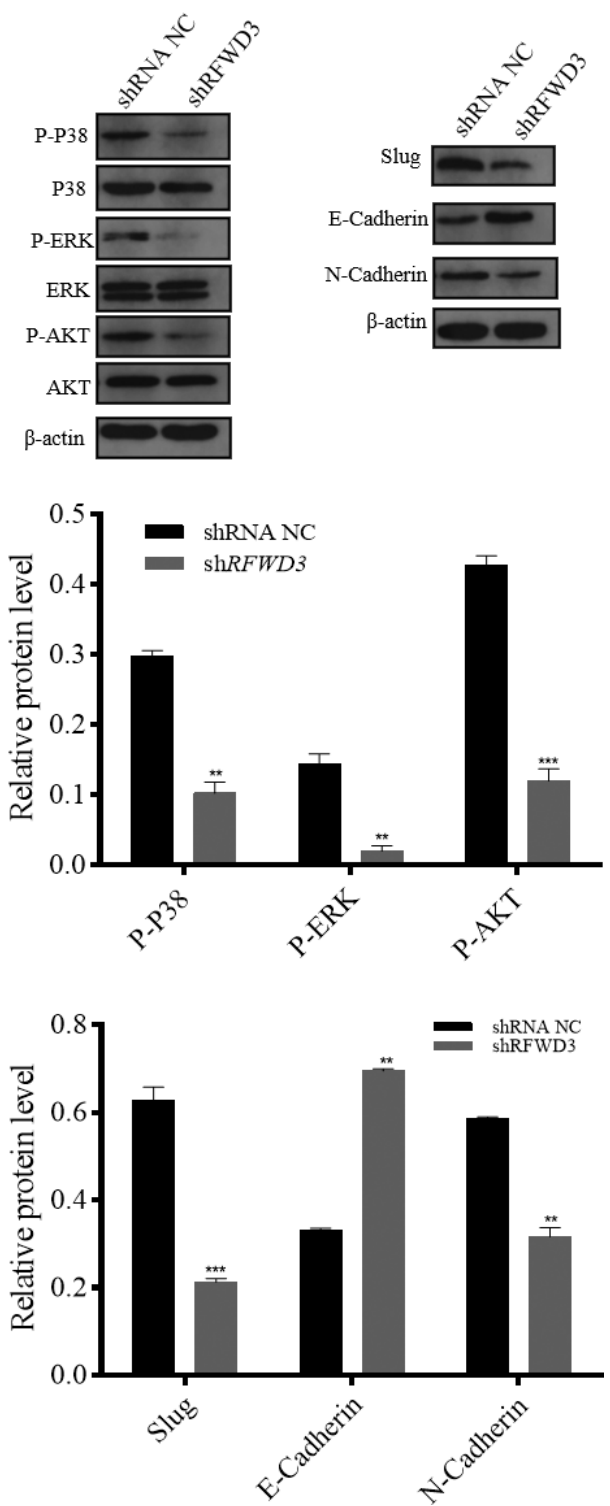

Figure 6. The AKT, ERK/P38 and Slug pathway-related proteins expression level of gastric cancer cells AGS (A) and HGC-27 (B) transfected with shRNA NC or shRFWD3. ${ }^{* *} p<$ $0.01,{ }^{* * *} p<0.001 v s$. shRNA NC. 
expression of RFWD3 in both AGS and HGC-27 cells. The results of MTT showed that down-regulation of RFWD3 expression increases the inhibitory of cells, which suggested RFWD3 is significantly associated with the development of gastric cancer. Moreover, our research showed that downregulation of RFWD3 expression promotes gastric cell apoptosis, suppresses gastric cell migration and invasion and arrests gastric cell cells in G2/M phase. In addition, we discovered that these alterations are related with AKT, ERK/ P38 and Slug pathways. Researches show that AKT, ERK/ P38 and Slug pathways are all involved in the regulation of various biological processes and promote tumorigenesis (Cho et al. 2019; Oliveira et al. 2019; Revathidevi et al. 2019). Moreover, the AKT, ERK/P38 and Slug pathways are activated by diverse cellular stimuli regulating various physiological functions such as cell growth, cell survival, cell cycle progression, protein translation and metabolism (Cho et al. 2019; Oliveira et al. 2019; Revathidevi et al. 2019). Our results showed that down-regulation of RFWD3 significantly decreases the P-P38, P-ERK, P-AKT, Slug and N-Cadherin protein expression levels in AGS and HGC-27 cells, while the expression level of E-Cadherin is increased, suggesting that the downregulated expression of RFWD3 in gastric cell lines activated AKT, ERK/P38 and Slug signaling pathway. These results showed that RFWD3-mediated AKT, ERK/ P38 and Slug signaling pathway may be one of the possible mechanisms of cell growth inhibition.

In conclusion, our results indicated that RFWD3 plays an accelerative role in the development of gastric carcinoma. Down-regulation of RFWD3 inhibited gastric cancer cells proliferation and promoted cell apoptosis. Moreover, downregulated expression of RFWD3 inhibited cell migration, invasion and arrested cell cycle through the regulation of AKT, ERK/P38 and Slug pathways in gastric cancer cells. RFWD3 may be a vital regulator of gastric tumorigenesis and an important therapeutic target for gastric carcinoma, which deserves further investigation.

Acknowledgments. The work was supported by the Shiyan Science and Technology Research and Development Plan (No. 17K72).

\section{References}

Adams JM, Cory S (2018): The BCL-2 arbiters of apoptosis and their growing role as cancer targets. Cell Death Differ. 25, 27-36 https://doi.org/10.1038/cdd.2017.161

Birkman EM, Mansuri N, Kurki S, Algars A, Lintunen M, Ristamaki R, Sundstrom J, Carpen, O (2018): Gastric cancer: immunohistochemical classification of molecular subtypes and their association with clinicopathological characteristics. Virchows. Arch. 472, 369-382 https://doi.org/10.1007/s00428-017-2240-x

Chung CC, Kanetsky PA, Wang Z, Hildebrandt MA, Koster R, Skotheim RI, Kratz CP, Turnbull C, Cortessis VK, Bakken AC, et al. (2013): Meta-analysis identifies four new loci associated with testicular germ cell tumor. Nat. Genet. 45, 680-685 https://doi.org/10.1038/ng.2634

Cho YA, Kim EK, Cho BC, Koh YW, Yoon SO (2019): Twist and snail/slug expression in oropharyngeal squamous cell carcinoma in correlation with Lymph Node Metastasis. Anticancer Res. 39, 6307-6316

https://doi.org/10.21873/anticanres.13841

Desterro J, Bak-Gordon P, Carmo-Fonseca M (2019): Targeting mRNA processing as an anticancer strategy. Nat. Rev. Drug Discov. 19, 121-129 https://doi.org/10.1038/s41573-019-0042-3

Esfandi F, Taheri M, Kholghi Oskooei V, Ghafouri-Fard S (2019): Long noncoding RNAs expression in gastric cancer. J. Cell Biochem. 120, 13802-13809 https://doi.org/10.1002/jcb.28653

Fu X, Yucer N, Liu S, Li M, Yi P, Mu JJ, Yang T, Chu J, Jung SY, O'Malley BW, et al. (2010): RFWD3-Mdm2 ubiquitin ligase complex positively regulates p53 stability in response to DNA damage. Proc. Natl. Acad. Sci. USA 107, 4579-4584 https://doi.org/10.1073/pnas.0912094107

Ferlay J, Soerjomataram I, Dikshit R, Eser S, Mathers C, Rebelo M, Parkin DM, Forman D, Bray F (2015): Cancer incidence and mortality worldwide: sources, methods and major patterns in GLOBOCAN 2012. Int. J. Cancer. 136, E359-E386 https://doi.org/10.1002/ijc.29210

Gong Z, Chen J (2011): E3 ligase RFWD3 participates in replication checkpoint control. J. Biol. Chem. 286, 22308-22313 https://doi.org/10.1074/jbc.M111.222869

Han YH, Mun JG, Jeon HD, Kee JY, Hong SH (2019): Betulin inhibits lung metastasis by inducing cell cycle arrest, autophagy, and apoptosis of metastatic Colorectal Cancer Cells. Nutrients 12,66 https://doi.org/10.3390/nu12010066

Inano S, Sato K, Katsuki Y, Kobayashi W, Tanaka H, Nakajima K, Nakada S, Miyoshi H, Knies K, Takaori-Kondo A, et al. (2017): RFWD3-mediated ubiquitination promotes timely removal of both RPA and RAD51 from DNA damage sites to facilitate homologous recombination. Mol. Cell 66, 622-634 https://doi.org/10.1016/j.molcel.2017.04.022

Jia Y, Zhao LM, Bai HY, Zhang C, Dai SL, Lv HL, Shan BE (2019): The tumor-suppressive function of miR-1296-5p by targeting EGFR and CDK6 in gastric cancer. Biosci. Rep. 39, 20181556 https://doi.org/10.1042/BSR20181556

Jiang Y, Zhang J, Zhao J, Li Z, Chen H, Qiao Y, Chen X, Liu K, Dong $Z$ (2019): TOPK promotes metastasis of esophageal squamous cell carcinoma by activating the Src/GSK3beta/STAT3 signaling pathway via gamma-catenin. BMC Cancer 19, 1264 https://doi.org/10.1186/s12885-019-6453-Z

Kitajima Y, Suzuki N, Nunomiya A, Osana S, Yoshioka K, Tashiro Y, Takahashi R, Ono Y, Aoki M, Nagatomi R (2018): The ubiquitin-proteasome system is indispensable for the maintenance of muscle stem cells. Stem Cell Reports 11, 1523-1538 https://doi.org/10.1016/j.stemcr.2018.10.009 
Knies K, Inano S, Ramirez MJ, Ishiai M, Surralles J, Takata M, Schindler D (2017): Biallelic mutations in the ubiquitin ligase RFWD3 cause Fanconi anemia. J. Clin. Invest. 127, 3013-3027 https://doi.org/10.1172/JCI92069

Lordick F, Shitara K, Janjigian YY (2017): New agents on the horizon in gastric cancer. Ann. Oncol. 28, 1767-1775 https://doi.org/10.1093/annonc/mdx051

Liu S, Chu J, Yucer N, Leng M, Wang SY, Chen BP, Hittelman WN, Wang Y (2011): RING finger and WD repeat domain 3 (RFWD3) associates with replication protein A (RPA) and facilitates RPA-mediated DNA damage response. J. Biol. Chem. 286, 22314-22322 https://doi.org/10.1074/jbc.M111.222802

Mitchell JS, Li N, Weinhold N, Forsti A, Ali M, van Duin M, Thorleifsson G, Johnson DC, Chen B, Halvarsson BM, et al. (2016): Genome-wide association study identifies multiple susceptibility loci for multiple myeloma. Nat. Commun. 7, 12050 https://doi.org/10.1038/ncomms12050

Ma ZH, Yang Y, Zou L, Luo KY (2019): 125I seed irradiation induces up-regulation of the genes associated with apoptosis and cell cycle arrest and inhibits growth of gastric cancer xenografts. J. Exp. Clin. Cancer Res. 31, 61 https://doi.org/10.1186/1756-9966-31-61

Mu JJ, Wang Y, Luo H, Leng M, Zhang J, Yang T, Besusso D, Jung SY, Qin J (2007): A proteomic analysis of ataxia telangiectasiamutated (ATM)/ATM-Rad3-related (ATR) substrates identifies the ubiquitin-proteasome system as a regulator for DNA damage checkpoints. J. Biol. Chem. 282, 17330-17334 https://doi.org/10.1074/jbc.C700079200

Oliveira MS, Barbosa MIF, de Souza TB, Moreira DRM, Martins FT, Villarreal W, Machado RP, Doriguetto AC, Soares MBP, Bezerra DP (2019): A novel platinum complex containing a piplartine derivative exhibits enhanced cytotoxicity, causes oxidative stress and triggers apoptotic cell death by ERK/p38 pathway in human acute promyelocytic leukemia HL-60 cells. Redox Biol. 20, 182-194 https://doi.org/10.1016/j.redox.2018.10.006

Russo AE, Strong VE (2019): Gastric cancer etiology and management in Asia and the West. Annu. Rev. Med. 70, 353-367 https://doi.org/10.1146/annurev-med-081117-043436

Rocken C (2017): Molecular classification of gastric cancer. Expert. Rev. Mol. Diagn. 17, 293-301 https://doi.org/10.1080/14737159.2017.1286985

Revathidevi S, Munirajan AK (2019): Akt in cancer: mediator and more. Semin. Cancer Biol. 59, 80-91 https://doi.org/10.1016/j.semcancer.2019.06.002

Wang J, Yun D, Yao J, Fu W, Huang F, Chen L, Wei T, Yu C, Xu H, Zhou X, et al. (2018): Design, synthesis and QSAR study of novel isatin analogues inspired Michael acceptor as potential anticancer compounds. Eur. J. Med. Chem. 144, 493-503 https://doi.org/10.1016/j.ejmech.2017.12.043

Yan R, Li K, Yuan DW, Wang HN, Zhang Y, Dang CX, Zhu K (2018): Downregulation of microRNA-4295 enhances cisplatin-induced gastric cancer cell apoptosis through the EGFR/PI3K/Akt signaling pathway by targeting LRIG1. Int. J. Oncol. 53, 2566-2578 https://doi.org/10.3892/ijo.2018.4595

Zhang Y, Zhao X, Zhou Y, Wang M, Zhou G (2019): Identification of an E3 ligase-encoding gene RFWD3 in non-small cell lung cancer. Front. Med. 14, 318-326 https://doi.org/10.1007/s11684-019-0708-6

Zhang C, Liang Y, Ma MH, Wu KZ, Zhang CD, Dai DQ (2018): Downregulation of microRNA-376a in gastric cancer and association with poor prognosis. Cell Physiol. Biochem. 51, 2010-2018

https://doi.org/10.1159/000495820

Received: January 5, 2020

Final version accepted: February 13, 2020 